\title{
Manajemen Panen Kelapa Sawit (Elaeis guineensis Jacq.) Berdasarkan Kriteria ISPO dan RSPO di Kebun Sei Batang Ulak, Kabupaten Kampar, Riau
}

\section{Harvest Management of Palm Oil (Elaeis guineensis Jacq.) Based on ISPO and RSPO Criteria in Sei Batang Ulak Estate, Kampar, Riau.}

\section{Yuanda Pangi Harahap, Ahmad Junaedi*}

\author{
Departemen Agronomi dan Hortikultura, Fakultas Pertanian, Institut Pertanian Bogor \\ Jalan Meranti, Kampus IPB Dramaga, Bogor 16680, Indonesia \\ Telp. \& Faks. 62-251-8629353 e-mail: agronipb@indo.net.id \\ *Penulis untuk korespondensi : junaedi_agr@yahoo.com
}

Disetujui 17 Mei 2017/Published online 22 Mei 2017

\begin{abstract}
The research activity held in Sei Batang Ulak estate PT Ciliandra Perkasa was to study about technical and managerial aspect in managing palm oil plantation, and specifically studying aspects of palm oil harvesting. Special aspect of harvesting learned by pasrticipating conduct harvest and carrying out observations on some of the components of the harvest in the estate to determine the effectiveness and efficiency of the harvest in the SBU estate. Observations shown that the existing harvest management was good enough, but it should be improved in order to obtain the optimum production of fresh fruit bunches. Some things that need to be evaluated include harvester number, the use of personal safety equipment, harvest target in term of quantity and fruit quality. Based on observations also showed that the aspect of the harvest has not been in accordance with the principle of Indonesian Sustainable Palm Oil (ISPO) and Roundtable Sustainable Palm Oil (RSPO). Some criteria of the ISPO and RSPO still not implemented yet, such as a lack of socialization and the obligation of workers to use personal protective equipment when working, bringing children when working in the field. Therefore, the SBU estate has not yet certified by the ISPO and RSPO.
\end{abstract}

Keywords : harvester, production, safety equipment

\begin{abstract}
ABSTRAK
Kegiatan penelitian yang dilaksanakan di kebun Sei Batang Ulak (SBU), PT.Ciliandra Perkasa ini bertujuan untuk mempelajari aspek teknis dan manajerial dalam Pengelolaan perkebunan kelapa sawit, dan secara khusus mempelajari aspek pemanenan kelapa sawit. Aspek khusus pemanenan dipelajari dengan cara ikut melaksanakan kegiatan panen dan melaksanakan pengamatan pada beberapa komponen panen di kebun untuk mengetahui keefektifan dan keefisienan kegaitan panen di kebun SBU. Pengamatan yang dilakukan menunjukkan bahwa manajemen panen yang sudah ada cukup baik, akan tetapi perlu ditingkatkan agar didapatkan produksi tandan buah segar (TBS) yang optimal. Beberapa hal yang perlu dievaluasi meliputi tenaga kerja panen yang masih kurang, penggunaan alat pelindung diri yang masih minim, target panen yang belum terpenuhi, dan mutu buah yang kurang baik. Berdasarkan hasil pengamatan juga menunjukkan bahwa aspek panen belum sesuai dengan prinsip Indonesian Sustainable Palm Oil (ISPO) dan Roundtable

Sustainable Palm Oil (RSPO). Belum diterapkannya kriteria ISPO dan RSPO ditunjukkan dari kurangnya sosialisasi dan mewajibkan kepada tenaga kerja untuk menggunakan alat pelindung diri ketika bekerja, membawa anak-anak pada saat kerja di lapangan. Oleh karena itu, kebun SBU belum mendapat sertifikasi ISPO maupun RSPO.
\end{abstract}

Kata kunci : alat pelindung diri, pemanen, produksi 


\section{PENDAHULUAN}

Kelapa sawit (Elaeis guineensis Jacq.) merupakan salah satu tanaman perkebunan yang mempunyai peran penting bagi sub sektor perkebunan. Selain itu, kelapa sawit juga merupakan tanaman yang efisien dalam menghasilkan minyak nabati. Permintaan masyarakat terhadap olahan minyak kelapa sawit sangat tinggi sehingga perkebunan kelapa sawit di Indonesia menjadi primadona yang mampu berkembang seperti sekarang dan bisa menjadi negara produsen kelapa sawit terbesar di dunia. Penggunaan minyak kelapa sawit di Eropa sebesar $19 \%$ dari total kebutuhan minyak dan lemak dengan volume impor 4,4 juta ton, dimana sebesar 1,7 juta ton berasal dari Indonesia pada Oktober 2004 hingga September 2005 (Oil World Monthly,2006). Berdasarkan hal tersebut, diperkirakan akan meningkat $11 \%$ pada tahun berikutnya. Volume ekspor komoditas kelapa sawit sampai dengan september 2014 mencapai 15,96 juta ton dengan nilai sebesar 12,75 juta US\$. Ekspor mengalami kenaikan sebesar 7,59\% jika dibandingkan dengan volume ekspor september 2013 sebesar 14,831 juta ton (Ditjenbun, 2014).

Laju pertumbuhan rata-rata luas areal kelapa sawit Indonesia dari tahun 2004 hingga tahun 2014 sebesar 7,67 \%. Luas areal kelapa sawit pada tahun 2014 mencapai 10,9 juta ha dengan produksi 29,3 juta ton CPO (Ditjenbun, 2014). Sedangkan jumlah penduduk meningkat setiap tahunnya, yang membutuhkan lahan untuk pemukiman. Oleh karena itu, upaya yang dapat dilakukan untuk meningkatkan produksi selain perluasan lahan adalah intensifikasi lahan. Intensifikasi lahan dapat didukung oleh manajemen yang baik agar produksi meningkat dan industri yang berkelanjutan. Manajemen yang efektif bisa berupa pengelolaan panen yang terpadu dan penerapan sistem budidaya yang berkelanjutan.

Panen merupakan titik awal dari produksi dan berkaitan dengan teknis budidaya. Keberhasilan panen tergantung pada kegiatan budidaya serta ketersediaan sarana untuk kegiatan pemanenan. Cara panen mempengaruhi kuantitas dan kualitas produksi. Menurut Pahan (2006), selama kegiatan panen dan pengangkutan tandan, asam lemak bebas (ALB) dapat meningkat dengan cepat dengan adanya luka-luka pada buah karena benturan mekanis yang dapat mempercepat proses hidrolisis serta meningkatkan proses oksidasi. Proses pemanenan kelapa sawit meliputi pekerjaan memotong tandan buah segar (TBS), memungut brondolan, dan mengangkut dari kebun ke tempat pengumpulan hasil (TPH) serta ke pabrik. TBS yang dipanen diangkut ke pabrik kelapa sawit (PKS) dengan menggunakan beberapa alternatif seperti truk, lori, dan traktor. TBS dan brondolan dikirim ke PKS maksimum dalam kurun waktu 24 jam setelah panen (Erningpraja dan Siahaan, 2005).

Manajemen panen yang efektif tidak cukup untuk mendapatkan produksi tinggi dan berkelanjutan. Penerapan konsep berkelanjutan secara keseluruhan pada pengembangan kelapa sawit di Indonesia juga harus dilakukan. Isu-isu lingkungan yang buruk terhadap kelapa sawit mendorong terbentuknya pengembangan industri kelapa sawit yang berkelanjutan. Kerjasama informal yang diprakarsai oleh World Wide Fund melatarbelakangi diadakannya pertemuan tentang konsep minyak sawit yang lestari pada tanggal 20 September 2012. Terbentuklah organisasi komite dan kerjasama terus berlanjut dengan diadakannya pertemuan meja bundar minyak sawit lestari (Roundtable on Sustainable Palm Oil). Produsen, pengolah, pedagang minyak sawit yang menjadi anggota RSPO harus memenuhi delapan prinsip dari RSPO (RSPO, 2013). Masalah penting yang berkaitan dengan penerapan prinsip dan kriteria RSPO pada perkebunan kelapa sawit di Indonesia adalah penggunaan cara-cara terbaik dalam pengelolaan perekebunan kelapa sawit terutama bagi petani rakyat (Agustira et al., 2005). Tanggung jawab pemilik kebun dan pengolah terhadap lingkungan sosial terutama hak masyarakat juga perlu perhatian khusus, mengingat banyaknya konflik karena masalah tersebut.

Indonesia juga merupakan negara pertama yang mewajibkan seluruh perusahaan kelapa sawit memiliki sertifikasi sustainable palm oil dengan cara membentuk ISPO (Indonesian Sustainable Palm Oil). Sertifikasi ISPO dibentuk bukan untuk menyaingi sertifikasi RSPO. Prinsip dan kriteria ISPO dibuat sebagai inisiatif dari pemerintah atas kesadaran bahwa pengelolaan sumberdaya alam termasuk perkebunan kelapa sawit harus dilakukan secara berkelanjutan (Pusat Penelitian dan Pengembangan Perkebunan, 2012). Sertifikasi RSPO bersifat sukarela sedangkan sertifikasi ISPO bersifat wajib untuk seluruh perusahaan kelapa sawit yang ada di Indonesia, sehingga ada keterikatan aturan dengan perusahaan.

Penelitian ini bertujuan untuk memperoleh pengalaman yang terampil dalam manajerial perkebunan kelapa sawit dan juga meningkatkan kemampuan teknis lapangan dengan melaksanakan kegiatan sesuai dengan lokasi kebun. Secara khusus, dapat meningkatkan keterampilan bekerja dalam pengelolaan pada aspek pemanenan kelapa sawit. 


\section{METODE PENELITIAN}

Kegiatan penelitian dilaksanakan di Kebun Sei Batang Ulak, PT. Ciliandra Perkasa, First Resources Group, Kabupaten Kampar, Riau. Kegiatan penelitian dilaksanakan selama 4 bulan yaitu mulai dari 1 Maret 2016 sampai dengan 30 Juni 2016. Pelaksanaan penelitian di lapangan dilakukan dengan metode kerja secara langsung. Metode penelitian yang dilaksanakan adalah melakukan pekerjaan langsung di kebun yang mencakup aspek teknis dan aspek manajerial. Kegiatan yang dilaksanakan selama penelitian meliputi kerja langsung di lapangan sebagai karyawan, pendamping mandor, dan pendamping asisten afdeling. Kegiatan yang dilaksanakan selama menjadi karyawan adalah pengendalian gulma secara manual dan kimia, pemupukan organik (janjangan kosong dan limbah cair) dan anorganik, Sensus pokok dan produksi, dan pemanenan. Kegiatan yang dilaksanakan selama menjadi pendamping mandor adalah mengawasi pekerjaan karyawan, melakukan pemeriksaan pekerjaan di lapangan, dan mengisi administrasi pada tingkat mandor. Kegiatan sebagai pendamping asisten meliputi membantu menyusun rencana kerja bulanan dan harian, mengawasi kerja mandor, mengisi administrasi di tingkat asisten, mengikuti rapat dan field day bersama staff kebun, mengambil data mutu buah dan efisiensi panen sebagai evaluasi kerja mandor dan karyawan. Pengumpulan data dan informasi yang dilakukan meliputi pengambilan data primer dan data sekunder. Data primer diperoleh melalui pengamatan langsung di lapangan selama kegiatan menjadi KHL, pendamping mandor, dan pendamping asisten afdeling. Data sekunder diperoleh dari data yang ada di kebun meliputi lokasi geografis kebun, keadaan iklim, luas areal dan tata guna lahan, produksi dan produktivitas, struktur organisasi perusahaan, dan peraturan atau norma baku perusahaan.

Pengamatan yang dilakukan selama penelitian untuk melengkapi data primer terdiri dari : (1) Angka kerapatan panen. Jumlah tanaman yang diamati adalah $5 \%$ dari populasi tanaman dalam blok yang akan dipanen. (2) Tenaga kerja panen. Pengamatan dilakukan melalui wawancara dengan asisten afdeling dan mandor panen untuk mengetahui jumlah tenaga panen yang aktif. Kemudian dibandingkan dengan kebutuhan tenaga panen seharusnya dibutuhkan. (3) Alat panen dan alat pelindung diri. Pengamatan dilakukan terhadap semua pemanen yang ada di afdeling. Alat kerja panen yang diamatai adalah egrek, fiber, gancu, karung, dan angkong. Alat pelindung diri (APD) yang diamati adalah helm, sepatu, dan kaca mata.
(4) Rotasi panen. Pengamatan dilakukan dengan cara wawancara dengan mandor terhadap rotasi panen di afdeling. Pengamatan dilakukan selama dua bulan berturut-turut. (5) Kapasitas panen. Pengamatan dilakukan terhadap 5 pemanen dengan tujuan membandingkan kapasitas antar pemanen dan cara panen yang digunakan. Kemudian kapasitas pemanen dibandingkan dengan standar perusahaan. (6) Pengangkutan hasil panen. Pengamatan dlakukan terhadap dump truck sebanyak dua trip dengan tiga kali ulangan. Parameter pengamatan adalah waktu pengangkutan, jumlah TBS yang diangkut, dan jarak pengangkutan. (7) Mutu Buah. Pengamatan dilakukan dengan mengambil 10 sampel TPH dengan tingkat kematangan yang diamati di setiap TPH berupa buah mentah, kurang matang, matang, lewat matang, dan tandan kosong (buah busuk).

Hasil pengamatan berupa data primer dan data sekunder. Data primer dan data sekunder dianalisis secara deskriptif dan kuantitatif. Analisis secara deskriptif digunakan untuk mendapatkan nilai rata-rata dan persentase untuk dibandingkan dengan standar yang berlaku dan literatur yang berhubungan dengan pengamatan yang dilakukan. Analisis kuantitatif berdasarkan uji t- student. Uji t- student digunakan untuk membandingkan variabel yang sudah diperoleh. Kebun Sei Batang Ulak (SBU) PT. Ciliandra Perkasa merupakan anak perusahaan dari First Resources Group. Kebun SBU terletak di Desa Siabu, Kecamatan Salo, Kabupaten Kampar, Provinsi Riau.

\section{Letak Geografis dan Wilayah Administratif}

Kebun SBU PT CLP terletak di Desa Siabu, Kecamatan Salo, Kabupaten Kampar, Provinsi Riau dengan kordinat $101^{\circ} 00$ '29" BT dan $0^{0} 137^{\prime} 7^{\prime \prime}-0^{0} 08^{\prime} 47^{\prime \prime}$ LU. Kebun SBU terletak jauh dari jalan raya Kota Bangkinang. Kebun SBU terletak kurang lebih $20 \mathrm{~km}$ dari kota bangkinang dan $88 \mathrm{~km}$ dari kota Pekanbaru, Provinsi Riau.

Luas Total kebun sei batang ulak adalah sebesar 6.647,71 ha. Total luas areal terbagi menjadi areal yang diusahakan, areal yang mungkin dapat ditanami, dan areal yang tidak bisa ditanami. Areal yang diusahakan meliputi areal kebun yang ditanami dengan luas 6.481,54 ha, kompleks pabrik sebesar 32,15 ha, dan areal prasarana kebun seperti perumahan, jalan, dan jembatan sebesar 35,22 ha. Areal yang ditanami dibagi menjadi 244 blok dan 7 afdeling.

Kebun Sei Batang Ulak (SBU), PT. Ciliandra Perkasa menggunakan bibit kelapa sawit varietas Marihat sebesar 90,98\% dan 
PNG sebesar 9,02\%. Kebun SBU tidak memiliki pembibitan yang dikembangkan sendiri di areal kebun. Tanaman kelapa sawit di Kebun SBU PT CLP terdiri dari 11 tahun tanam berbeda, yaitu tahun tanam 1993, 1994, 1995, 1996, 1997, 1998, 1999, 2000, 2001, 2004, dan 2005. Data produksi dan produktivitas Kebun SBU PT CLP dapat dilihat di Tabel 1.

Tabel 1. Produksi dan produktivitas kebun SBU PT CLP tahun 2011 - 2015

\begin{tabular}{llllll}
\hline Tahun & Luas (ha) & $\begin{array}{l}\text { Produksi TBS } \\
\text { (Janjang) }\end{array}$ & Produksi (ton) & Produktivitas (ton/ha) & $\begin{array}{l}\text { Berat janjang } \\
\text { rata-rata (kg) }\end{array}$ \\
\hline 2011 & 6481.5 & 8985609 & 153627.8 & 23.7 & 17.1 \\
2012 & 6481.5 & 8387216 & 153621.9 & 23.7 & 18.3 \\
2013 & 6481.5 & 7434531 & 146384.5 & 22.5 & 19.7 \\
2014 & 6481.5 & 7100659 & 150004.0 & 23.1 & 21.1 \\
2015 & 6481.5 & 6951214 & 158487.6 & 24.4 & 22.8 \\
Rata-rata & 6481.5 & 7696029 & 152425.2 & 23.5 & 19.8 \\
\hline
\end{tabular}

Sumber: Kantor Kebun SBU PT CLP (2016)

Pada Tabel 1 dapat dilihat bahwa produksi kelapa sawit Kebun SBU tahun 2011 sampai tahun 2015 mengalami penurunan dan juga kenaikan dengan luasan yang relatif sama. Produksi kebun mengalami kenaikan pada tahun 20132105 secara tonase, tetapi mengalami penurunan secara produksi TBS dari tahun 2011-2015. Produksi secara tonase mengalami kenaikan karena berat janjang rata-rata (BJR) mengalami kenaikan juga setiap tahunnya.

Jenis tanah adalah tanah mineral atau ultisol dengan kelas lahan S-3. Curah hujan tahunan selama 5 tahun terakhir (2011-2015) kurang merata sepanjang tahun. Jumlah hari hujan pertahun rata-rata 147 hari dan rata-rata curah hujan adalah $215 \mathrm{~mm} / \mathrm{bulan}$.

\section{HASIL DAN PEMBAHASAN}

Panen merupakan salah satu faktor yang menentukan kualitas dan kuantitas produksi. Pemanenan kelapa sawit merupakan salah satu kegiatan yang penting pada pengelolaan tanaman kelapa sawit. Tanaman kelapa sawit umumnya sudah mulai dipanen pada umur tiga tahun. Keberhasilan panen sangat ditentukan dari hasil produksi kebun, meliputi tandan, minyak, dan inti sawit (Sunarko, 2010). Keberhasilan panen akan menunjang pencapaian produktivitas tanaman, sebaliknya kegagalan panen akan menghambat pencapaian produktivitas tanaman kelapa sawit. Kegiatan panen dibagi menjadi beberapa tahap, yaitu perencanaan panen, pelaksanaan panen, dan evaluasi panen.

\section{Perencanaan Panen}

Perencanaan panen merupakan tahapan yang penting untuk melaksanakan kegiatan panen. Beberapa hal yang perlu diperhatikan dalam perencanaan panen adalah melakukan sensus angka kerapatan panen (AKP) untuk menentukan taksasi produksi dan juga menentukan kebutuhan tenaga kerja pada hari panen tersebut. Penentuan blok untuk melaksanakan sensus AKP berpedoman tehadap pusingan panen.

\section{Angka kerapatan panen}

Angka kerapatan panen (AKP) merupakan angka yang menunjukkan seberapa banyak produksi yang didapat dari satu hari panen. AKP digunakan untuk membuat rencana panen dari hasil taksasi produksi. AKP didapat dari perbandingan antara janjang yang siap dipanen dengan jumlah tanaman sampel yang akan dipanen. Jumlah tanaman sampel yang digunakan adalah sebanyak 3-5\% dari jumlah seluruh tanaman yang akan dipanen. Penentuan kematangan buah pada saat melakukan sensus AKP mengikuti kriteria kematangan buah yang ada di kebun. Kriteria kematangan buah dapat berbeda-beda di setiap kebun. Kriteria panen di kebun SBU dapat dilihat pada Tabel 2.

Tabel 2. Kriteria panen di kebun SBU

\begin{tabular}{|c|c|}
\hline Kategori & Kriteria \\
\hline Mentah & $\begin{array}{l}\text { Tidak ada berondolan yang } \\
\text { terlepas }\end{array}$ \\
\hline Kurang Matang & $\begin{array}{l}<2 \text { Berondolan } / \mathrm{kg} \text { terlepas } \\
2 \text { Berondolan } / \mathrm{kg} \text { hingga } 75 \%\end{array}$ \\
\hline Matang & $\begin{array}{l}\text { berondolan bagian luar } \\
\text { terlepas }\end{array}$ \\
\hline Lewat Matang & $\begin{array}{l}>75 \%-90 \% \text { berondolan telah } \\
\text { lepas }\end{array}$ \\
\hline Janjang Kosong & $\begin{array}{l}>90 \% \text { Berondolan telah } \\
\text { lepas }\end{array}$ \\
\hline
\end{tabular}

Sumber: Kantor Kebun SBU PT CLP (2016)

Berdasarkan hasil pengamatan AKP pada Tabel 3 menunjukkan bahwa rata-rata AKP di Afdeling I Kebun Sei Batang Ulak PT. CLP sebesar10,79\%. Kisaran nilai AKP 25\% - 100\% menunjukkan produksi tinggi, $15 \%$ - 20\% menunjukkan produksi sedang, dan kurang dari 15\% menunjukkan produksi rendah (Tobing 
dalam Akbar 2008). Rata-rata angka kerapatan panen di Afdeling 1 kebun SBU tergolong rendah Tabel 3. Hasil taksasi dan realisasi produksi di afdeling I kebun SBU

\begin{tabular}{lcrrrrr}
\hline \multirow{2}{*}{ Tanggal } & \multicolumn{3}{c}{ Rencana } & \multicolumn{2}{c}{ Aktual } & \multicolumn{2}{c}{ Selisih } \\
\cline { 2 - 7 } & $\begin{array}{l}\text { AKP } \\
(\%)\end{array}$ & Produksi (janjang) & Produksi (kg) & Produksi (janjang) & $\begin{array}{l}\text { Produksi } \\
(\mathrm{kg})\end{array}$ & $\begin{array}{l}\text { produksi } \\
(\%)\end{array}$ \\
\hline 26 April & 9.93 & 2.42 & 52.44 & 2.07 & 44.88 & -14.40 \\
$12 \mathrm{Mei}$ & 11.38 & 1.75 & 41.29 & 1.69 & 39.89 & -3.40 \\
$19 \mathrm{Mei}$ & 11.06 & 1.85 & 45.60 & 1.62 & 42.82 & -6.10 \\
Rata-rata & 10.79 & 2.00 & 46.45 & 1.79 & 42.53 & -8.00 \\
\hline
\end{tabular}

Tabel 4. Hasil uji $t$ terhadap produksi taksasi dan aktual di afdeling I Kebun SBU

\begin{tabular}{lcc}
\hline Panen & Rata-rata AKP $(\%)$ & $\begin{array}{c}\text { Rata-rata Produksi } \\
(\mathrm{Kg})\end{array}$ \\
\hline Rencana & 10.79 & 46446 \\
Aktual & 9.72 & 42530 \\
Hasil Uji $t$ & $*$ & $*$ \\
\hline
\end{tabular}

Keterangan : * = Berbeda nyata pada taraf 5\%

Hasil uji t-student pada Tabel 4 yang membandingkan hasil taksasi dengan aktual menunjukkan bahwa rata-rata AKP dan produksi TBS berbeda nyata antara taksasi dan aktual. Hal tersebut menunjukkan bahwa perhitungan taksasi AKP dan produksi belum akurat terhadap hasil AKP dan produksi aktual. Hasil yang belum akurat dapat disebabkan beberapa hal karena kurang dari $15 \%$.

seperti luas panen aktual yang tidak sesuai dengan luas panen yang direncanakan, perbedaan persepsi terhadap kriteria kematangan buah antara pemanen dengan orang yang melaksanakan AKP, dan kesesuaian data populasi di lapangan dengan administrasi.

\section{Tenaga kerja panen}

Tenaga panen dibagi menjadi beberapa kemandoran untuk memudahkan pembagian hanca panen serta pengawasan pada saat panen. Tenaga kerja merupakan peran utama dalam pelaksanaan kegiatan panen. Jumlah tenaga panen di Afdeling 1 kebun SBU sebanyak 33 orang. Afdeling 1 memiliki rata-rata luas kaveld panen sebesar 166,7 ha. Penentuan kebutuhan tenaga kerja bergantung pada besarnya nilai AKP. Fluktuasi nilai AKP dari bulan februari sampai juni 2016 dapat dilihat pada Gambar 1.

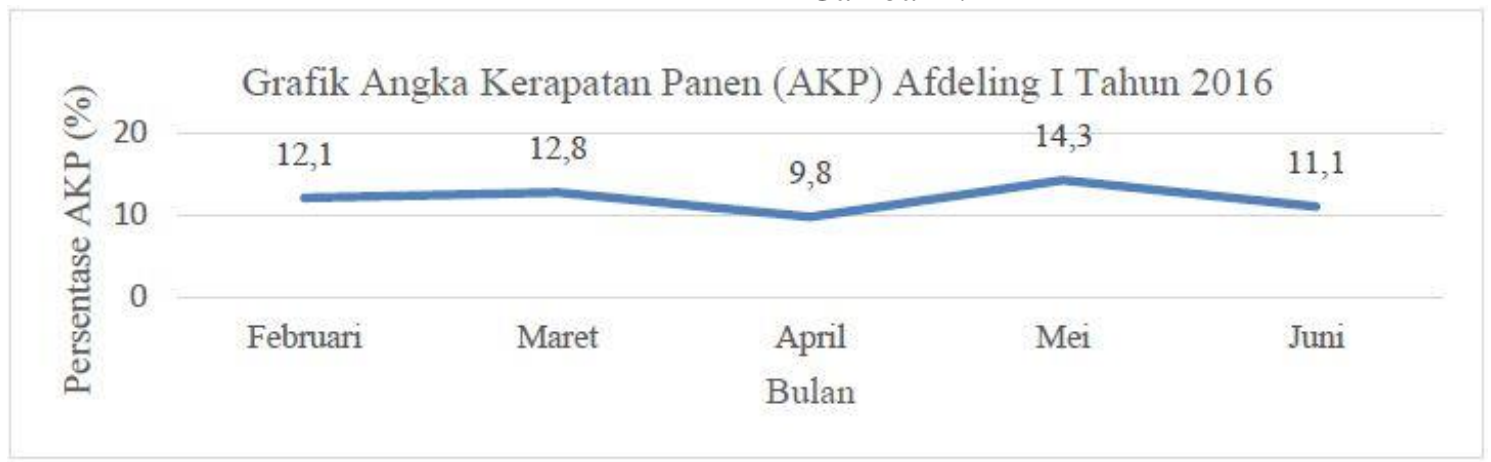

Gambar 1. Fluktuasi nilai AKP tahun 2016

Kebutuhan tenaga panen (AKP rendah)

$=\frac{A \times B \times C}{E}$

$=\frac{166.7 \mathrm{ha} \times 9.8 \% \times 24.4 \mathrm{~kg} \times 132 \mathrm{tanaman}}{2400 \mathrm{~kg}}$

$=21.7$ orang $\sim 22$ orang

Kebutuhan tenaga panen (AKP tinggi)

$=\frac{A \times B \times C}{E}$

$=\frac{166.7 \mathrm{ha} \times 14.3 \% \times 22.6 \mathrm{~kg} \times 132 \text { tanaman }}{2400 \mathrm{~kg}}$
$=29.6$ orang $\sim 30$ orang

Berdasarkan perhitungan jumlah tenaga kerja yang dilakukan di Afdeling I pada AKP terendah dan dan tertinggi menunjukkan bahwa kebutuhan tenaga kerja tercukupi dengan tenaga kerja yang ada sebanyak 33 orang. Jumlah tenaga kerja yang dibutuhkan pada AKP terendah adalah sebanyak 22 orang dan pada AKP tertinggi sebanyak 30 orang. Kelebihan jumlah tenaga panen di afdeling dialihkan pada kegiatan yang lain seperti pemeliharaan jalan, penunasan, dan operator alat langsir buah, sedangkan kekurangan 
tenaga kerja diambil dari tenaga panen afdeling lain atau mengurangi total luasan yang akan dipanen.

\section{Pusingan panen}

Pusingan panen adalah jumlah frekuensi masuk dalam kaveld dalam satuan waktu tertentu. Pembagian kaveld panen menyesuaikan dengan standar pusingan yang ada di kebun. Afdeling I kebun SBU membagi kaveld menjadi 6 dengan standar pusingannya yaitu 6/7. Hasil pengamatan terhadap pusingan panen dapat dilihat pada Tabel 5.

Tabel 5. Pusingan panen di afdeling I kebun SBU

\begin{tabular}{|c|c|c|c|}
\hline \multirow[b]{2}{*}{ Bulan } & \multicolumn{3}{|c|}{ Pusingan panen } \\
\hline & $\begin{array}{c}\text { Standar } \\
\text { perusahaan }\end{array}$ & Terpanjang & Terpendek \\
\hline April & 7 & 15 & 5 \\
\hline Mei & 7 & 12 & 6 \\
\hline $\begin{array}{l}\text { Rata- } \\
\text { rata }\end{array}$ & 7 & 13.5 & 5.5 \\
\hline
\end{tabular}

Berdasarkan hasil pengamatan pusingan panen pada Tabel 5 selama dua bulan di Afdeling I kebun SBU menunjukkan bahwa rata-rata pusingan terpanjang selama dua bulan adalah 13,5 hari dan pusingan terpendeknya adalah 5,5 hari. Jika dibandingkan dengan standar pusingan perusahaan, maka pusingan panen di Afdeling I belum memenuhi kriteria. Pusingan panen berpengaruh langsung terhadap mutu buah dan mutu hanca. Pusingan yang terlalu cepat dapat menyebabkan terpanennya buah mentah oleh pemanen. Pusingan yang terlalu lama akan memicu banyaknya kehilangan hasil dari brondolan dan buah tinggal, serta memperlambat pekerjaan pemanen karena harus banyak mengutip brondolan.

Pelaksanaan Panen

Tabel 9. Hasil Pengamatan transportasi panen di Afdeling 1 kebun SBU

\begin{tabular}{|c|c|c|c|c|c|c|}
\hline Ulangan & $\begin{array}{c}\text { Waktu } \\
\text { tempuh ke } \\
\text { blok (menit) }\end{array}$ & $\begin{array}{l}\text { Waktu muat } \\
\text { (menit) }\end{array}$ & $\begin{array}{c}\text { Waktu } \\
\text { tempuh ke } \\
\text { PKS (menit) }\end{array}$ & $\begin{array}{l}\text { Total waktu } \\
\text { (menit) }\end{array}$ & $\begin{array}{c}\text { Jarak } \\
\text { Tempuh }(\mathrm{km})\end{array}$ & Muatan truk $(\mathrm{kg})$ \\
\hline 1 & 7.5 & 147.0 & 9.8 & 164.3 & 8.5 & 9160,0 \\
\hline 2 & 11.1 & 170.0 & 16.5 & 197.6 & 12.5 & 8460,0 \\
\hline 3 & 10.2 & 166.8 & 14.0 & 191.0 & 15.0 & 9670,0 \\
\hline Rata-rata & 9.6 & 161.3 & 13.4 & 184.3 & 12.0 & 9096,7 \\
\hline \multicolumn{4}{|c|}{$\begin{array}{ccc}\text { Berdasarkan } & \text { hasil pengamatan } \\
\text { pengangkutan pada Tabel } 9 \text { menunjukkan bahwa }\end{array}$} & \multicolumn{3}{|c|}{$\begin{array}{l}\text { rata-rata waktu yang dibutuhkan untuk } \\
\text { mengangkut TBS sampai ke PKS adalah } 184,3 \\
\text { menit dengan jarak yang ditempuh sejauh } 12 \mathrm{~km}\end{array}$} \\
\hline \multicolumn{4}{|l|}{192} & \multicolumn{3}{|c|}{ Yuanda Pangi Harahap, Ahmad Junaedi } \\
\hline
\end{tabular}
merupakan salah satu hal yang akan memudahkan pelaksanakan kegiatan panen. Persiapan panen yang baik saja belum cukup untuk mendapatkan hasil yang terbaik, jika faktor-faktor terkait prosedur pelaksanaan seperti alat panen, alat pelindung diri pekerja, kapasitas pemanen, basis premi panen, dan transportasi buah tidak diawasi dengan baik.

\section{Alat panen dan alat pelindung diri (APD)}

Pelaksanaan panen yang baik harus didukung juga oleh alat panen yang memadai. Alat panen yang tidak lengkap akan menghambat kegiatan dan memicu terjadinya penurunan kapasitas dari pemanen. Salah satu hal yang perlu dilakukan dalam mempersiapkan pelaksanaan pekerjaan panen adalah penyediaan alatalat kerja (Pahan 2006). Alat panen yang digunakan untuk kegiatan panen meliputi, egrek atau dodos, angkong, traktor superbull, gancu, kapak, karung, dan tojok.

Berdasarkan pengamatan yang dilakukan terhadap kelengkapan dan kondisi alat panen di Afdeling I kebun SBU. Alat panen yang dimiliki oleh pemanen umumnya lengkap, akan tetapi tidak semua kondisinya baik untuk digunakan. Alat yang sering mengalami kerusakan pada saat pelaksanaan panen adalah pisau egrek, karena yang paling dominan digunakan dalam kegiatan panen. Penggantian alat yang rusak juga membutuhkan waktu yang cukup lama, karena kebun tidak memiliki stok untuk alat-alat panen. Panen merupakan kegiatan yang sangat rentan terhadap terjadinya kecelakaan kerja. Perusahaan bertanggung jawab atas kecelakaan yang terjadi pada saat jam kerja seperti pengobatan dan juga pencegahan. Pencegahan yang dapat dilakukan adalah dengan cara menghimbau pekerja untuk menggunakan alat pelindung diri pada saat bekerja. Alat pelindung diri yang digunakan pada saat panen meliputi helm, sepatu boot, dan juga kaca mata. Pengamatan terhadap persentase penggunaan APD di Afdeling 1 Kebun SBU dapat di lihat pada Tabel 6. yang sudah dibuat. Perencanaan panen yang baik 
dan bermuatan $9.096 \mathrm{~kg} /$ trip. Budget produksi Afdeling I kebun SBU tahun 2016 adalah sebesar

$57.100 \mathrm{~kg} / \mathrm{hari}$. Apabila dalam satu trip rata-rata muatan $9.096 \mathrm{~kg} /$ trip dengan waktu 184,3 menit, maka untuk satu unit dump truck harus memenuhi kebutuhan budget sebanyak 3 trip dengan waktu 552,9 menit atau lebih kurang 9 jam/hari. Berdasarkan pengamatan terhadap waktu pengangkutan, maka kegiatan

pengangkutan belum efektif. Kegiatan belum efektif, karena waktu yang dibutuhkan untuk memenuhi budget adalah selama 9 jam, sementara jam kerja di kebun hanya 7 jam kerja. Beberapa faktor yang mempengaruhi kelancaran transportasi, yaitu kecepatan pemanen dalam mengeluarkan buah ke TPH, alat pengangkutan yang lengkap dan baik, serta kondisi jalan yang memadai untuk akses pengangkutan TBS. Semakin lama pemanen melangsir buah ke TPH, maka semakin lama pula proses pengangkutan selesai. Kondisi jalan yang rusak juga akan

mempengaruhi proses mengangkut buah. Jalan yang becek akan menghambat akses mobil untuk lewat, sehingga menyebabkan mobil tidak bisa jalan karena licin.

\section{Mutu buah}

Pengecekan terhadap mutu buah atau yang sering disebut grading berguna untuk memastikan buah yang terkirim ke PKS merupakan buah yang sudah sesuai dengan SOP kematangan buah perusahaan. Grading biasanya dilakukan secara rutin oleh mandor panen dan kerani produksi sebelum buah diangkut dari $\mathrm{TPH}$, dan juga oleh asisten dan manajer kebun setelah buah terkirim ke PKS. Setiap kebun memiliki kriteria masing-masing dalam menentukan kematangan buah. Kriteria kematangan buah dibuat agar persepsi dalam menentukan kematangan buah bisa sama antara mandor yang melaksanakan sensus AKP dengan pemanen yang melaksanakan kegiatan panen. Pengamatan terhadap mutu buah dilakukan di Afdeling I kebun SBU dengan menggunakan kriteria kebun SBU (Tabel 10).

Tabel 10. Hasil Grading TBS di Afdeling 1 Kebun SBU

\begin{tabular}{|c|c|c|c|c|c|c|}
\hline Blok & $\begin{array}{l}\text { Jumlah } \\
\text { tandan }\end{array}$ & $\begin{array}{l}\text { Buah mentah } \\
(\%)\end{array}$ & $\begin{array}{l}\text { Buah kurang } \\
\text { matang }(\%)\end{array}$ & $\begin{array}{l}\text { Buah matang } \\
(\%)\end{array}$ & $\begin{array}{l}\text { Buah lewat } \\
\text { matang }(\%)\end{array}$ & Janjang kosong \\
\hline F20 & 169 & 0 & 1.8 & 92.9 & 4.7 & 0,6 \\
\hline E18-20 & 182 & 0 & 0.5 & 95.6 & 3.8 & 0,0 \\
\hline E22-23 & 213 & 0 & 0.0 & 93.9 & 6.1 & 0,0 \\
\hline E26-27 & 149 & 0 & 0.7 & 92.6 & 6.7 & 0,0 \\
\hline D21 & 131 & 0 & 3.1 & 94.7 & 1.5 & 0,8 \\
\hline \multicolumn{2}{|c|}{ Rata-rata } & 0 & 1.2 & 93.9 & 4.6 & 0.3 \\
\hline \multicolumn{2}{|c|}{ Standar } & 0 & 0.0 & 99.5 & 0.5 & 0.0 \\
\hline
\end{tabular}

Berdasarkan hasil pengamatan terhadap kriteria kematangan buah pada Tabel 10 menunjukkan bahwa rata-rata buah yang terpanen di Afdeling I belum memenuhi standar yang sudah ditentukan oleh perusahaan. Buah matang yang terpanen hanya sebesar $93.9 \%$ dari standar sebesar $99.5 \%$. Selain itu, masih terdapat buah kurang matang sebesar $1.2 \%$ dari standar $0 \%$ dan lewat matang $4.6 \%$ dari standar $0.5 \%$. Kematangan buah dipengaruhi langsung oleh angka pusingan panen. Tingginya persentase buah lewat matang diakibatkan oleh pusingan panen yang terlalu panjang, sehingga menyebabkan banyak buah matang yang tidak terpanen pada panen-panen sebelumnya. Sedangkan, adanya buah kurang matang dikarenakan kesalahan dari pemanen dalam memanen TBS. Kematangan buah yang dipanen memperngaruhi kualitas CPO yang dihasilkan dari pengolahan TBS.

Kesesuaian manajemen panen dengan ISPO dan $R S P O$

Kriteria ISPO dan RSPO tidak mengatur secara langsung dan detail kegiatan pemanenan. Beberapa kriteria yang berhubungan dengan panen diatur pada prinsip ISPO nomor dua tentang manajemen perkebunan dan prinsip nomor lima tentang tanggung jawab terhadap pekerja (Tabel 11).

Tabel 11. Kesesuaian kriteria ISPO dengan manajemen panen

\begin{tabular}{llll}
\hline Kriteria & Deskripsi & Keadaan di kebun & Kesesuaian \\
\hline
\end{tabular}




\subsubsection{7}

Melakukan panen tepat waktu dengan cara yang baik dan benar dan mencatat produksi TBS.

\subsubsection{1}

Harus memastikan bahwa TBS yang dipanen harus segera diangkut ke tempat pengolahan untuk menghindari penurunan kualitas.

\section{2}

Harus meningkatkan kesejahteraan dan kemampuan pekerja sesuai peraturan perundangundangan.

5.3

Dilarang mempekerjakan anak di bawah umur dan melakukan diskriminasi sesuai peraturan perundangundangan.

Berdasarkan perbandingan antara prinsip dengan keadaan di kebun, Kebun SBU belum sepenuhnya sesuai dengan prinsip-prinsip ISPO yang terkait dengan manajemen panen. Kriteria 2.2.2.1 belum sepenuhnya sesuai karena ketidaktepatan waktu dalam menganhkut buah yang telah dipanen menuju PKS, masih sering

Tabel 12. Kesesuaian kriteria RSPO dengan manajemen panen

\begin{tabular}{|c|c|c|c|}
\hline Kriteria & Deskripsi & Keadaan di kebun & Kesesuaian \\
\hline 4.7 & $\begin{array}{l}\text { Peraturan keselamatan dan kesehatan kerja } \\
\text { didokumentasikan, dikomunikasikan dan } \\
\text { dilaksanan secara efektif }\end{array}$ & $\begin{array}{l}\text { Peraturan tentang } \\
\text { keselamatan kerja belum } \\
\text { sepenuhnya diterapkan, } \\
\text { rendahnya persentase } \\
\text { penggunaan alat pelindung } \\
\text { diri pada saat bekerja }\end{array}$ & Belum sesuai \\
\hline 4.8 & $\begin{array}{l}\text { Semua staf, pekerja, petani dan kontraktor } \\
\text { dilatih dengan baik }\end{array}$ & $\begin{array}{l}\text { Pelatihan diberikan kepada } \\
\text { setiap jenjang karyawan } \\
\text { maupun stafyang akan bekerja } \\
\text { di kebun SBU }\end{array}$ & Sesuai \\
\hline 5.3 & $\begin{array}{l}\text { Limbah dikurangi, didaur ulang, dimanfaatkan } \\
\text { kembali dan dibuang dengan cara yang } \\
\text { bertanggung jawab terhadap lingkungan sosial }\end{array}$ & $\begin{array}{l}\text { Pemanfaatan limbah } \\
\text { diterapkan melalui } \\
\text { penyusunan pelepah di } \\
\text { gawangan mati, penggunaan } \\
\text { janjang kosong dan limbah } \\
\text { cair sebagai pupuk organik }\end{array}$ & Sesuai \\
\hline
\end{tabular}

kriteria 4.8 dan 5.3 sudah sesuai dengan prinsip dan pada kriteria 4.7 belum sesuai dengan prinsip

Diantara beberapa kriteria yang berhubungan langsung dengan kegiatan panen, terdapat buah restan di hanca maupun TPH. Prinsip yang terdapat pada RSPO juga ada yang sama dengan sebagian prinsip yang diatur pada ISPO. Penjelasan juga terdapat pada RSPO prinsip nomor 4 kriteria $4.7,4.8$, dan prinsip nomor 5 kriteria 5.3 (Tabel 12).
Pengangkutan dilakukan segera Belum Sesuai

Perusahaan sudah menerapkan Sesuai

Tidak ada anak di bawah umur Sesuai
Perusahaan perkebunan cara panen sesuai dengan teknis setelah buah berada di TPH, dan sangat menghindari buah yang belum terangkut dalam panen, hanya saja belum terangkut di TPH. sistem penggajian baku, tersedianya sarana dan juga terdapat asuransi untuk karyawan.

Perusahaan perkebunan yang dipekerjakan. 
memenuhi prinsip-prinsip yang sudah diatur pada ISPO maupun RSPO dan dapat memperoleh sertifikasi.

\section{KESIMPULAN}

Kegiatan penelitian memberikan pengalaman dan pengetahuan kepada mahasiswa tentang hal-hal teknis dan manajerial dalam pengelolaan perkebunan kelapa sawit. Berdasarkan hasil pengamatan langsung di lapangan, wawancara, serta ikut melaksanakan pekerjaan menunjukkan bahwa manajemen pemanenan di Afdeling I kebun SBU perlu ditingkatkan untuk mendapatkan produksi yang optimal dan sesuai dengan rencana manajemen. Manajemen perlu ditingkatkan karena jumlah tenaga kerja yang kurang, rendahnya kesadaran tenaga kerja menggunakan alat pelindung diri ketika bekerja, belum terpenuhinya standar output panen yang ditentukan oleh manajemen, rotasi panen yang panjang, dan tidak tercapainya standar kematangan buah yang dipanen. Semua komponen panen tersebut harus diperbaiki agar tidak berdampak terhadap kegiatan panen yang lain. Kesesuain terhadap ISPO dan RSPO belum seluruhnya diterapkan di Afdeling I kebun SBU, dan kebun SBU juga belum memiliki sertifikasi ISPO.

\section{DAFTAR PUSTAKA}

Agustira M.A., Nurkhoiry R., Dja'far. 2005. Pedoman Roundtable Sustainable Palm Oil (RSPO) tentang prinsip dan kriteria sustainable palm oil pada industri kelapa sawit. Jurnal Penelitian Kelapa Sawit 13(2): 85-101.

Akbar A. 2008. Manajemen panen di perkebunan kelapa sawit (Elaeis guineensis Jacq.) Pantai Bunai Estate, PT Sajang Heulang,
Minamas Plantation, Tanah Bumbu, Kalimantan Selatan [skripsi]. Bogor (ID): Institut Pertanian Bogor

[Ditjenbun] Direktorat Jenderal Perkebunan. http://ditjenbun.pertanian.go.id/.[8 Januari 2016].

Erningpraja L. dan Siahaan D. 2005. Penerapan good agriculture practice dan good manufacture practice dalam meningkatkan mutu dan keamanan pangan minyak kelapa sawit. Jurnal Penelitian Kelapa Sawit 13(3): 109-118.

Oil World Monthly. 2006. Ista Mielke Gmbh, Langenberg 25, 21007. Hamburg, Germany. Pahan I. 2006. Panduan Lengkap Kelapa Sawit. Penebar Swadaya, Jakarta.

Pusat Penelitian dan Pengembangan Perkebunan. 2012. Pengelolaan Kelapa Sawit Berpedoman ISPO. [Internet] [diunduh 2016 Jan 03] tersedia pada http://www.perkebunan.litbang.pertanian.g o.id

[RSPO] Roundtable Sustainable Palm Oil. 2013: Principles and Criteria for the Production of Sustainable Palm Oil. [Internet] [diunduh 2015 Des 14] tersedia pada http://www.rspo.org/

Setyamidjaja D. 2006. Kelapa Sawit; Teknik Budidaya, Panen, dan Pengolahan. Yogyakarta (ID):Kanisius.

Sunarko. 2010. Budidaya dan Pengelolaan Kebun Kelapa Sawit dengan Sistem Kemitraan. Jakarta (ID): PT AgroMedia Pustaka. 